\title{
Asbestos-Related Lung Disorder
}

National Cancer Institute

\section{Source}

National Cancer Institute. Asbestos-Related Lung Disorder. NCI Thesaurus. Code

C84472.

A disorder affecting the lungs due to asbestos exposure. Examples include asbestosis and lung carcinoma. 